\title{
Covid-19 Salgininın BIST-100 Endeksi Üzerindeki Etkisi: Türkiye Özelinde Ampirik Bir Araştırma
}

\author{
Mustafa Kartal ${ }^{1 *}$, Ümit Dağl1 ${ }^{2}$

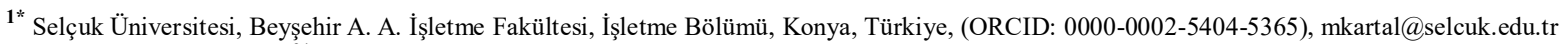 \\ $2^{* *}$ Selçuk Üniversitesi, Sosyal Bilimler Enstitüsü, Konya, Türkiye, umitdagli51@outlook.com
}

(İlk Geliş Tarihi 11 Ağustos 2021 ve Kabul Tarihi 17 Aralık 2021)

(DOI: 10.31590 /ejosat.981801)

ATIF/REFERENCE: Kartal, M. \& Dağlı, Ü. (2021). Covid-19 Salgınının BIST-100 Endeksi Üzerindeki Etkisi: Türkiye Özelinde Ampirik Bir Araştırma. Avrupa Bilim ve Teknoloji Dergisi, (31), 815-822.

$\ddot{O} \mathbf{z}$

2019 yılının Aralık ayında Çin'in Hubei eyaleti Wuhan kentinde ilk olarak görülen ve daha sonra bütün dünyaya hızla yayılan Covid19 salgını, ülkelerin sağlı hizmetlerinin yanı sıra sosyal ve ekonomik yapılarını da ciddi anlamda tehdit etmektedir. Bu çalışmada, Covid-19 süresince BIST-100 endeksinin performansı FMOLS ve DOLS yöntemleri kullanılarak analiz edilmiştir. Çalışmada; BIST100 endeksi, hasta sayısı ve vefat sayısı 17 Mart 2020-21 Ocak 2021 dönemi için günlük olarak ele alınmıştır. BIST-100 endeksi bağımlı, hasta sayısı ve vefat sayısı açıklayıcı değişken olarak ele alınmıştır.Elde edilen sonuçlar, COVID-19'un BIST-100 endeksi üzerinde olumsuz etkisi olduğu göstermektedir. Buna göre hasta sayısı bir birim arttığında BIST-100 endeksi 0,04 birim değer kaybetmektedir.

Anahtar Kelimeler: Covid-19 Salgını, BIST-100 Endeksi, Türkiye.

\section{The Effect of the Covid-19 Epıdemic on BIST-100 Index: An Empirical Research Special in Turkey}

\begin{abstract}
The Covid-19 epidemic, which was first seen in Wuhan, China's Hubei province in December 2019 and then spread rapidly all over the world, seriously threatens the social and economic structures of countries as well as health services. In this study, the performance of the BIST-100 index during Covid-19 was analyzed using FMOLS and DOLS methods. In the study; the BIST-100 index, the number of patients and the number of deaths are discussed on a daily basis for the period 17 March 2020-21 January 2021. BIST-100 index was considered as dependent, number of patients and number of deaths as explanatory variables. The results obtained show that COVID-19 has a negative effect on the BIST-100 index. Accordingly, when the number of patients increases by one unit, the BIST100 index loses 0.04 units.
\end{abstract}

Keywords: Covid-19 Epidemic, BIST-100, Turkey.

*Sorumlu Yazar: $\underline{\text { mkartal@selcuk.edu.tr }}$ 


\section{Giriş}

2019 yılının Aralık ayında Çin'in Hubei eyaleti Wuhan kentinde ilk olarak görülen ve daha sonra bütün dünyaya hızla yayılarak korku ve panik durumuna yol açan koronavirüsten kaynaklanan hastalığına, Dünya Sağlık Örgütü/World Health Organization (DSÖ/WHO) tarafindan 11 Şubat 2020 tarihinde "Covid-19" adı verilmiştir. Virüsün yayılma hızı ve ülkelerin salgınla mücadele konusunda çekimser/geç davranmaları 12 Mart 2020'de Covid-19' unun pandemik bir hastalık olarak ilan edilmesinin temel gerekçeleri arasında yer almıştır.

Covid-19 salgınına ilişkin aşıların etkinliği, virüsün mutasyona uğrama durumu ve salgının ekonomik etkileri gibi birçok belirsizlik bulunmaktadır. Dünya Bankası tarafından Haziran 2020'de açıklanan Küresel Ekonomik Beklentiler raporunda, 2020'de küresel ekonominin \%5,2 daralacağı tahmin edilmiştir. Ülkelerin uyguladıkları maliye ve para politikalarına rağmen GSYH'deki bu düşüşün, son dönemlerdeki en şiddetli ekonomik resesyon olduğu belirtilmiştir. Covid-19 salgınının küresel ekonomide yaratmış olduğu temel etkiler ekonomik şu şekilde sıralanabilir (OECD, 2020):

- Borsalarda düşüş,

- İşsizlik oranlarında artış,

- Seyahat ve turizm sektöründe daralma,

- Tüketici güven endeksindeki düşüş,

- Tedarik zincirlerinde aksaklıklar,

- Sanayi üretim endeksinde azalma.

Bu çalışmada, Türkiye özelinde Covid-19 sürecinin borsalar üzerindeki etkisi analiz edilecektir. Çalışmanın giriş bölümünün ardından ikinci bölümde Covid-19 salgını ile ilgili genel bilgilere ve gelişmelere yer verilmektedir. Üçüncü bölümde literatür taraması sunulacak olup; dördüncü bölümde veri seti, yöntem ve analiz sonuçları yorumlanacaktır. Çalışma sonuç ve öneriler ile tamamlanacaktır.

\section{Covid-19 Salgını}

Covid-19 salgını, 2019 yılının Aralık ayında Çin'in Hubei eyaleti Wuhan kentinde ilk olarak görülen ve daha sonra bütün dünyaya hızla yayılarak korku ve panik durumuna yol açmıştır.

Tablo 2. Ülkelere Göre Vaka ve Ölüm Sayılart

\begin{tabular}{|c|c|c|c|}
\hline Ülkeler & Vaka Sayıları & Ölüm Savıları & Ölüm Oranı* \\
\hline Amerika Birlesik Devlerleri & 19.346 .790 & 335.789 & 1,74 \\
\hline Hindistan & 10.286 .709 & 148.994 & 2,54 \\
\hline Brezilya & 7.619 .200 & 193.875 & 1,81 \\
\hline Rusva & 3.186 .336 & 57.555 & 2,49 \\
\hline Fransa & 2.576 .420 & 64.254 & 2.95 \\
\hline Íngiltere & 2.488 .784 & 73.512 & 3.52 \\
\hline İtalva & 2.107 .166 & 74.159 & 2,66 \\
\hline İspanya & 1.893 .502 & 50.442 & 1,93 \\
\hline Almanya & 1.742 .661 & 33.624 & \\
\hline
\end{tabular}

EBOLA, SARS ve MERS gibi salgınlarından daha az ölümcül sonuçlara yol açmasına rağmen Covid-19 hastalığının söz konusu salgınlara kıyasla daha bulaşıcı bir nitelikte olması endişenin boyutunu artırmaktadır.

Covid-19 ve diğer salgınların ölüm ve bulaşıcılık oranlarına Tablo 1'de yer verilmektedir.

Tablo 1. COVID-19 ve Diğer Salgınların Ölüm/Bulaşıcık Oranlart

\begin{tabular}{|c|c|c|}
\hline & $\begin{array}{c}\text { Ölüm Oranı } \\
\text { (Ölüm sayısı/Vaka } \\
\text { sayısı) }\end{array}$ & $\begin{array}{c}\text { Bulaşıcılık Oranı } \\
\text { (Enfekte kişi } \\
\text { başına) }\end{array}$ \\
\hline Ebola & $\% 50$ & $1.5-2.5$ \\
\hline MERS & $\% 34.30$ & $0.42-0.92$ \\
\hline SARS & $\% 10$ & 3 \\
\hline Covid-19 & $\% 1-3.4$ & $1.5-3.5$ \\
\hline $\begin{array}{c}\text { Mevsimsel } \\
\text { Grip }\end{array}$ & $\% 0.05$ & 1.3 \\
\hline
\end{tabular}

Kaynak: Abiad vd., 2020: 1.

Tablo 1 incelendiğinde, Covid-19 kaynaklı ölüm oranının $\% 1$ ile \%3,4 aralığında değiştiği tahmin edilmektedir. Bu oran, SARS hastalığında \%10 olarak gerçekleşmişken; MERS için \%34 olarak hesaplanmıştır. Ancak Covid-19'dan kaynaklanan ölüm oranının mevsimsel grip ölüm oranından önemli ölçüde yüksek seyretmektedir.

Küresel olarak 1 Ocak 2021 tarihi itibariyle yaklaşık 82 milyon insanın bu hastalığa yakalandığı ve enfekte olan insanlardan 1.808.041'inin ise hayatını kaybettiği Dünya Sağlı Örgütü tarafından açıklanmıştır. Nitekim hastalığın kalıcı bir hasar bırakıp bırakmadığı konusunda yeterince bilimsel çalışma bulunmamaktadir.

Ülkelere göre Covid-19 vaka sayıları ve ölüm sayıları Tablo 2'de ortaya konmaktadır. 
European Journal of Science and Technology

\begin{tabular}{|c|c|c|c|}
\hline Kolombiva & 1.626 .461 & 42.909 & 2,64 \\
\hline Ariantin & 1.613 .928 & 43.163 & 2,67 \\
\hline Meksika & 1.413 .935 & 124.897 & 8,83 \\
\hline Türkiye & 1.394 .314 & 20.881 & 1,50 \\
\hline Polonya & 1.305 .774 & 28.956 & 2,22 \\
\hline Dünva & 81.197 .503 & 1.808 .041 & 2.23 \\
\hline
\end{tabular}

* Ölüm oranı, toplam vaka sayısı içerisinde yaşanan ölüm durumunu temsil etmektedir. İlgili değer, ölüm sayısı*100/vaka sayısı formülü aracılı̆̆ıyla hesaplanmıştır.

Kaynak: World Health Organization, 2021.

Tablo 2'ye göre, Covid-19 salgınına karşı mücadelede en disiplinli ve başarılı ülkelerden birisi Türkiye olmuştur. Ölüm oranı göstergesi dikkate alındığında; dünya ortalamasının altında olan Türkiye, tabloda yer alan diğer ülkelerden daha başarılı bir durumdadır. Nitekim Covid-19 salgınının dünya üzerindeki olumsuz etkileri, aşı çalışmalarını hızlandırmışır. Ancak aşıların bütün dünyada uygulanmaya başlamasına rağmen İngiltere'de ortaya çıkan ve diğer ülkelere de yayılan mutasyonun daha bulaşıcı olduğuna yönelik açıklamalar endişe ve panik durumunu sürdürmektedir.

Kısa sürede içerisinde bütün dünyaya hızla yayılan Covid19 karşısında tüm ülkeler bir yandan sosyal hayatta çeşitli kısıtlamaları hayata geçirmişken; diğer yandan salgının ekonomi üzerinde etkisini hafifletebilmek amaciyla farklı politikaları hayata geçirmişlerdir. Ülkelerin hayata uygulamaya koymuş

oldukları politikaların başarısı destek paketlerinin büyüklüğüne, içeriğine ve paketin uygulanmaya konulma zamanına göre farklılık göstermektedir (Eichenbaum vd., 2020). EIU (2020), ülkelerin Covid-19 ile mücadelesinin kalitesini ölçmek için bir endeks geliştirmiş̧ir. $\mathrm{Bu}$ endeks; iki alt başlıkta hesaplanmaktadır. Yanıt kalitesi başlı̆̆ında; test sayısı, Covid-19 dışı sağlık hizmetlerinin sunulması ve ortalamanın üzerindeki aşırı ölümlerin sayısı kireçlerinden oluşurken; önceden var olan risk faktörleri arasında ise yaşlı nüfusun payı, obezite yaygınlığı ve uluslararası gelenlerin sayısı dikkate alınmıştır.

21 OECD ülkesi özelinde hazırlanan endeks değerlerine Grafik 1'de yer verilmektedir.

Grafik 1. Ülke Siralamasina Göre EIU Endeks Değerleri

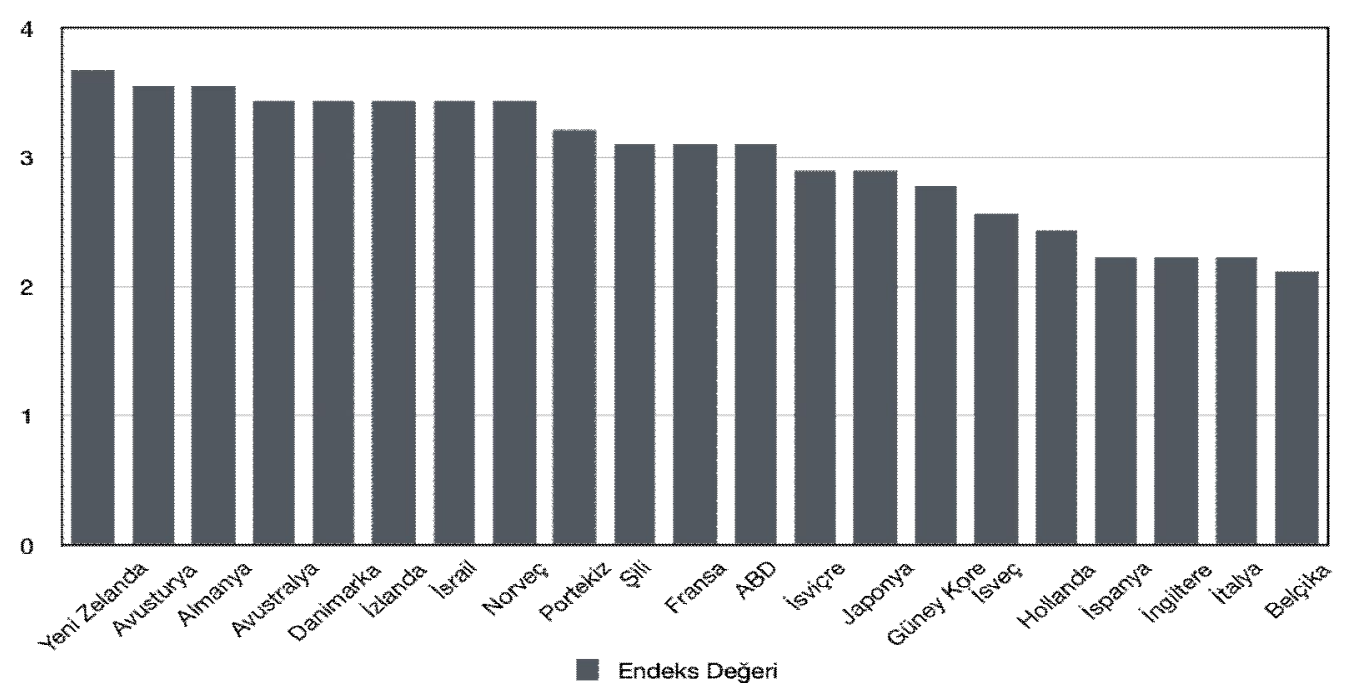

Bu endeks, 21 OECD ülkesinin koronavirüs salgınına karşı ne derece iyi tepki verdiğini ortaya koymak amcayla geliştirilmiştir. Endeks değerleri, risk profillerine göre hangi ülkelerin salgını en iyi şekilde yönettiği hakkında bilgiler vermektedir (Economist Intelligence Unit, 2020).

Kaynak: Economist Intelligence Unit (2020).

Grafik 1 göz önünde bulundurulduğunda; Yeni Zelanda, Avusturya, Almanya, Avustralya, Danimarka, İzlanda, İsrail ve Norveç'in üst sıralarda yer aldığı görülmektedir. Bu ülkelerin Covid-19 salgınına karşı başarısının temelinde hızlı ve erken davranmak ile önemli izleme ve test programları yürütmek yer

e-ISSN: 2148-2683 almaktadır. Buna karşın; İspanya, İngiltere, İtalya ve Belçika, Avrupa'da salgından en çok etkilenen ve salgınla mücadele en başarısız endeks değerine sahip ülkeler olarak ortama çıkmaktadır (Konig ve Winkler, 2020: 225). 


\section{Yazın Taraması}

Literatürde, Covid-19'un ekonomik etkilerini uygulamalı olarak araştıran çalışmalar bulunmaktadır. Literatür taramasında Covid-19'un ekonomik etkilerini tahmin eden çeşitli çalışmalara yer verilmiştir.

Hatmanu vd. 2021 yılında yaptıkları çalışma, 11 Mart 2020 ile 30 Nisan 2021 arasındaki dönemi kapsamaktadır. Covid19'un borsa üzerindeki etkisini ölçmek için ARDL eşbütünleşme testi kullanılmış olup; sonuçlar salgının Romanya için BET endeksi üzerinde önemli bir uzun vadeli olumsuz etkisi olduğunu göstermiştir.

Hong vd. (2021), Covid-19'un borsa performansı üzerindeki etkisini araştırdıkları çalışmalarında, ABD ekonomisi özelinde 1 Ocak 2019-30 Haziran 2020 dönemine ait veri setini kullanmışlardır. Bai ve Perron (1998, 2003), Elliot ve Mullier (2004) ve $\mathrm{Xu}$ (2013) tarafindan geliştirilen metodolojiden yararlanılarak yapılan analizlerden elde edilen bulgular, salgınının yaratmış olduğu ekonomik koşulların piyasa verimsizliği ile ilişkili olduğunu ortaya koymaktadır.

Davis vd. (2021), Şubat ortasından Mayıs 2020'nin sonlarına kadar 35 ülke özelinde hisse senetleri değerlerine ilişkin günlük verileri ele almışlardır. Küresel hisse senedi fiyatları, sosyal hareketlilik azalmadan önce 17 Şubat'tan 12 Mart'a kadar yüzde 30 düşüş göstermiştir. Bu tarihten sonraki 11 gün içinde, hisse senetleri yüzde 10 daha değer kaybetmiştir. 23 Mart'tan 9 Nisan'a kadar, hisse senetleri kayıpları kısmen giderilmiş olup; 9 Nisan'dan Mayıs sonuna kadar hisse senetleri fiyatları önemli ölçüde yükselmiştir.

Baker vd. (2020), araştırmalarında ABD borsasının Covid19'a önceki salgınlara göre çok daha güçlü tepki vermediğine ilişkin kanıtlar sunmuşlardır.

Khatatbeh vd. (2020), küresel hisse senedi piyasalarının Covid-19'a ani tepkisini ampirik olarak incelemeyi amaçlamışlardır. Hisse senedi fiyat endekslerinin günlük veri serilerini kullanan yazarlar, salgının hisse senedi getirileri üzerinde önemli bir olumsuz etkisi olduğunu belirtmişlerdir. Ayrıca, bu etkiler, hasatlığın küresel bir salgın olarak ilan edildiği 11 Mart 2020'de daha da belirgin olmuştur.

He vd. (2020) yapmış oldukları çalışmalarında; Çin Halk Cumhuriyeti, İtalya, Güney Kore, Fransa, İspanya, Almanya, Japonya ve Amerika Birleşik Devletleri özelinde Covid-19'un borsa üzerindeki etkisini geleneksel t-testleri ve parametrik olmayan Mann-Whitney testleri kullanarak araştırmışlardır. Elde edilen bulgular, COVID-19'un etkilenen ülkelerin borsaları üzerinde olumsuz ancak kısa vadeli bir etkiye sahip olduğunu ortaya koymaktadır.

Topçu ve Gülal (2020) çalışmasında, 10 Mart 2020-30 Nisan 2020 döneminde COVID-19'un gelişmekte olan borsalar üzerindeki etkisini sıradan en küçük kareler (OLS) regresyon yöntemini kullanarak tahmin etmiştir. Analiz sonuçları, salgının gelişen borsalar üzerindeki olumsuz etkisinin giderek azaldığını göstermektedir.

Öztürk vd. (2020)'e göre, borsa endeksi Türkiye'de bildirilen vaka sayısından etkilenmektedir. Çalışma kapsamında yöntem olarak sabit etkili regresyon tekniği tercih edilmiştir. Elde edilen bulgulara göre, metal ürünler, makine ve spor, sigorta ve bankacılık sektörleri Covid-19 salgınından en çok etkilenen sektörler olmuşlardır. Ayrıca salgından en az etkilenen sektörler ise yiyecek-içecek, toptan ve perakende ticaret ve gayrimenkul yatırım sektörleri olarak sıralanmıştır.

Anh ve Gan (2020) çalışmalarında, 30 Ocak 2020-30 Mayıs 2020 dönemine ati verileri ele almışlardır. Panel veri regresyon modelleri kullanılarak yapılan analizlerde Covid-19'un Vietnam'ın hisse senedi getirileri üzerinde önemli ve olumsuz bir etkiye sahip olduğunu belirtmişlerdir. Ayrıca finans sektörünün COVID-19 salgını sırasında Vietnam borsasında en çok etkilenen sektörlerinin başında gelmiştir.

Özdemir (2020) çalışmasında, 12 Mart 2020-31 Ağustos 2020 dönemi için Covid-19 salgınının BIST sektör endekslerine etkisini incelemiştir. Değişkenler arasındaki ilişki Hatemi-J asimetrik nedensellik testi ile tahmin edilmiş olup; analiz sonuçları vaka sayısı ile mali endeks arasındaki negatif ilişkiye işaret etmektedir. Bunun yanı sıra vefat sayısı ile mali endeks arasında ise nedensellik ilişkisi bulunmamıştır.

\section{Veri Seti, Yöntem ve Bulgular}

Çalışmada; Türkiye özelinde BIST-100 endeksi, hasta sayısı ve vefat sayısı 17 Mart 2020-21 Ocak 2021 dönemi için günlük olarak ele alınmıştır. BIST-100 endeksi bağımlı, hasta sayısı ve vefat sayısı açıklayıcı değişken olarak ele alınmıştır. Covid19'un BIST-100 endeksi üzerindeki etkilerinin değerlendirilmesinde kullanılan veriler Tablo 3 'te sunulmuştur.

\section{Tablo 3. Veri Seti}

\begin{tabular}{|c|l|}
\hline BIST-100 & $\begin{array}{l}\text { Bu değişken, Borsa İstanbul'da işlem gören piyasa ve işlem hacmi açısından en yüksek 100 hisse senedinin } \\
\text { performansını göstermektedir. }\end{array}$ \\
\hline Vefat sayısı & Covid-19 kaynaklı günlük vefat sayısını temsil etmektedir. \\
\hline Hasta sayısı & Covid-19 kaynaklı günlük hasta sayısını ifade etmektedir. \\
\hline
\end{tabular}

* BIST-100 endeksine ilişkin değerler, https://tr.investing.com/indices/ise-100 adresinden temin edilmiştir.

** Vefat sayısı ve hasta sayısına ilişkin değerler, https://covid19.saglik.gov.tr/TR-66935/genel-koronavirus-tablosu.html adresinden alınmıştır.

Değişkenlere ait tanımlayıcı istatistikler Tablo 4 'te ortaya konmaktadır. 
European Journal of Science and Technology

Tablo 4. Tanımlayıcı İstatistikler

\begin{tabular}{|c|c|c|c|}
\hline & BIST-100 & Hasta Sayıs & Vefat Sayısı \\
\hline Ortalama & 1159.173 & 2187.854 & 80.65728 \\
\hline Medyan & 1126.990 & 1614.000 & 62.00000 \\
\hline Max. & 1569.350 & 7381.000 & 259.0000 \\
\hline Min. & 842.4600 & 168.0000 & 2.000000 \\
\hline Std. & 167.7594 & 1596.192 & 70.53388 \\
\hline Çarpıklık & 0.614772 & 1.572033 & 1.112261 \\
\hline Basıklık & 3.015449 & 4.704869 & 4.128271 \\
\hline Jarque-Bera & 13.41915 & 113.5266 & 17180.00 \\
\hline Toplam & 246903.9 & 466013.0 & 1054706. \\
\hline Sum Sq. Dev. & 5966360. & $5.40 \mathrm{E}+08$ & 213 \\
\hline Gözlemler & 213 & 213 & \\
\hline
\end{tabular}

Serinin durağan seviyelerinin incelenmesi ekonometrik incelemelerde önemli bir yere sahiptir. Bu çalışmada, serinin

durağanlığı Augmented Dickey-Fuller (ADF) testi kullanılarak test edilmiştir. Bu testlerin sonuçları Tablo 5'te sunulmuştur.

Tablo 5. ADF Birim Kök Testi Sonuçlart

\begin{tabular}{|c|c|c|}
\hline Değişkenler & I0 & I1 \\
\hline BIST-100 & 0.4812 & 0.0000 \\
\hline Hasta sayısı & 0.6300 & 0.0000 \\
\hline Vefat Saysı & 0.6830 & 0.0000 \\
\hline
\end{tabular}

Tablo 5 incelendiğinde, BIST-100 değişkeninin düzeyde

bütünleşme testini uygulamadan önce, aşağıdaki tablodaki (bkz. durağan olmadığı anlaşılmaktadır. Bu nedenler değişkenlerin tablo 6) gecikme uzunluğu seçimine bakmamız gerekmektedir.

Tablo 6. Uygun Gecikme Uzunluğunun Belirlenmesi

\begin{tabular}{|c|c|c|c|c|c|}
\hline Lag & $\log L$ & LR & FPE & AIC & SC \\
\hline $\mathbf{0}$ & -4124.738 & NA & $6.19 \mathrm{e}+13$ & 40.27061 & 40.31924 \\
\hline 1 & -2962.849 & 2278.435 & $8.07 \mathrm{e}+08$ & 29.02292 & $29.21744^{*}$ \\
\hline 2 & -2948.143 & 28.40914 & $7.64 \mathrm{e}+08^{*}$ & $28.96724 *$ & 29.30765 \\
\hline 3 & -2945.395 & 5.226110 & $8.12 \mathrm{e}+08$ & 29.02825 & 29.51454 \\
\hline 4 & -2941.916 & 6.517190 & $8.57 \mathrm{e}+08$ & 29.08211 & 29.71429 \\
\hline 5 & -2931.953 & $18.37173 *$ & $8.49 \mathrm{e}+08$ & 29.07271 & 29.85078 \\
\hline
\end{tabular}


Avrupa Bilim ve Teknoloji Dergisi

\begin{tabular}{|c|c|c|c|c|c|}
\hline Lag & LogL & LR & FPE & AIC & SC \\
\hline $\mathbf{6}$ & -2928.086 & 7.016725 & $8.94 \mathrm{e}+08$ & 29.12279 & 30.04675 \\
\hline $\mathbf{7}$ & -2922.141 & 10.61334 & $9.21 \mathrm{e}+08$ & 30.22245 \\
\hline $\mathbf{8}$ & -2917.634 & 7.915733 & $9.64 \mathrm{e}+08$ & 29.19643 & 30.41216 \\
\hline
\end{tabular}

Tablo 6'ya göre, AIC ikinci gecikmede en küçük değere sahip olduğundan ikinci gecikme seçilmiştir. Değişkenler aynı düzeyde durağan hale getirildikten sonra değişkenler arasındaki ilişkiyi incelemek amacıyla eş bütünleşme testi uygulanmıştır. Eş bütünleşme testi sonucu Tablo 7' de verilmiştir.

Tablo 7. Eş Bütünleşme Testi Sonuçları

\begin{tabular}{|c|c|c|c|c|}
\hline Hipotez & & Trace & 0.05 & Kritik Değer \\
\hline No. of CE(s) & Öz değer & İstatistik & 29.79707 & 0.0022 \\
\hline Hiçbiri* & 0.101788 & 40.23932 & 15.49471 & 0.0229 \\
\hline En çok 1* & 0.072589 & 17.69611 & 3.841466 & 0.1714 \\
\hline En çok 2 & 0.008870 & 1.870913 & & \\
\hline
\end{tabular}

Tablo 7 incelendiğinde, değişkenler arasında ortak entegrasyon bulunmaktadır. AS'deki değer, sıfır hipotezini reddeden tablonun ilk satırındaki $\% 5$ ten küçüktür. Değişkenler arasında ortak entegrasyon olduğunda FMOLS veya DOLS yöntemleri kullanılabilmektedir. FMOLS ve DOLS sonuçları Tablo 8'de özetlenmektedir.

Tablo 8. FMOLS ve DOLS Sonuçlart

\begin{tabular}{|c|c|c|c|c|}
\hline \multicolumn{5}{|c|}{ FMOLS Sonuçları } \\
\hline Değişken & Katsayı & Std. Hata & t-istatistik & Olasilık \\
\hline Hasta Sayısı & -0.045956 & 0.013227 & -3.474374 & 0.0006 \\
\hline Vefat Sayısı & 2.470293 & 0.299496 & 8.248155 & 0.0000 \\
\hline $\mathrm{C}$ & 1059.234 & 26.99799 & 39.23380 & 0.0000 \\
\hline $\mathrm{r} 2$ & 0.594353 & \multicolumn{2}{|c|}{ Ortalama bağımlı değişken } & 1157.323 \\
\hline Düzeltilmiş r2 & 0.590472 & \multicolumn{2}{|c|}{ S.D. bağımlı değişken } & 165.9621 \\
\hline S.E. of regresyon & 106.2064 & \multicolumn{2}{|c|}{ Kalan toplamın karesi } & 2357480 \\
\hline \multirow[t]{2}{*}{ Uzun dönem varyans } & 51786.96 & & & \\
\hline & \multicolumn{4}{|c|}{ DOLS Sonuçları } \\
\hline Değişken & Katsayı & Std. Hata & t-istatistik & Olasılık \\
\hline Hasta Sayısı & -0.045599 & 0.016345 & -2.789676 & 0.0058 \\
\hline Vefat Sayısı & 2.411988 & 0.341971 & 7.053199 & 0.0000 \\
\hline $\mathrm{r} 2$ & 1062.730 & 28.81965 & 36.87518 & 0.0000 \\
\hline Düzeltilmiş r2 & 0.603868 & Ortal & "ğişken & 1156.739 \\
\hline
\end{tabular}


European Journal of Science and Technology

\begin{tabular}{|c|c|c|c|}
\hline S.E. of regression & 0.588102 & S.D. bağımlı değişken & 163.0743 \\
\hline S.E. of regresyon & 104.6600 & Kalan toplamın karesi & 2201696. \\
\hline Uzun dönem varyans & 51524.73 & & \\
\hline
\end{tabular}

Tablo 8'deki FMOLS ve DOLS sonuçları incelendiğinde hasta sayısının BISST-100 endeksine olumsuz etkisi bulunmaktadır. Buna göre, hasta sayısı bir birim arttı̆̆ında BIST-100 endeksi 0,04 birim değer kaybetmektedir.

\section{Sonuç, Değerlendirme ve Öneriler}

2019 yllında Çin'de ortaya çıkan ve bütün dünya yayılan Covid-19 salgını, milyonlarca insanın hayatını kaybetmesine neden olurken; aynı zamanda küresel ekonominin ciddi bir resesyona girmesine zemin hazırlamıştır. Salgından bu yana tedarik zincilerindeki aksaklıklar ve turizm sektöründeki daralma başta olmak üzere milyonlarca insan işini kaybederek geçim sıkıntısı ile mücadele etmek zorunda kalmıştır. Bunun yanı sıra salgının seyri ve ne zaman sonuçlanacağına ilişkin belirsizlikler küresel ekonomideki şok dalgasını devam ettirmektedir. Covid-19 salgınından kaynaklanan ekonomik ortamda, küresel yoksulluk 1998 yılından bu yana ilk kez artış eğilimine girmiş̧tir. Salgınla mücadele kapsamında okulların kapatılması, evde eğitime eşit olmayan erişim ve aileler üzerindeki ekonomik baskı gelecek dönemlerde sosyo-ekonomik maliyetler yaratabilecektir. Salgının kontrol altına alınabilmesi amacıyla yurt içi ve yurt dışı seyahatlere getirilen sinırlandırmalar nedeniyle salgının ilk dönemlerinde havayolu seferlerinde keskin düşüşler yaşanmıştır. Bunun yanı sıra doğrudan yabancı yatırımların daralması ve tedarik zincirlerindeki aksalıklar ülkeleri ekonomik açıdan zor durumda bırakmıştır.

$\mathrm{Bu}$ çalışmada, Covid-19 süresinin BIST-100 indeksi üzerindeki etkileri konu edinmiştir. Çalışma kapamında 17 Mart 2020-21 Ocak 2021 dönemi için BIST-100 endeksi bağıml, hasta sayısı ve vefat sayısı açıklayıcı değişken olarak ele alınmıştır. FMOLS ve DOLS analiz sonuçları hasta sayısının BİST-100 endeksi üzerinde olumsuz etki yarattığı ortaya koymaktadır. Buna göre hasta sayısı bir birimlik artış BIST-100 endeksinin 0,04 birim değer kaybetmesiyle sonuçlanacaktır.

Covid-19 salgınının etkileri; hastalık özelliklerine, demografik özelliklere ve ülkeler arası gelişmişilik düzeyine bağlı olarak değişmektedir. Söz konusu etkilerin azaltılabilmesi için aşağıda belirtilen çözüm önerilerinin olumlu sonuçlar vereceği düşünülmektedir:

- Vergi borçlarının ertelenmesi ya da vergi muafiyeti,

- Gümrük tariflerinde indirim

- Tedarik zincilerinin genişletilmesi

- Diş ticarette yeni pazar arayışı

- Özel sektöre yönelik kredi desteği,

- Firmaların e-ticaret faaliyetlerine yönelmeleri,

- Nakdi yardım gibi iç talebi artıracak uygulamalar.

Covid-19 salgını, gerek mal piyasasında gerekse de işgücü piyasasında arz-talep dengesininin bozulmasına yol açmıştır.
Üretici ve tüketici talebinin dinamik bir karaktere sahip olması bu dengesizliğinin temelini oluşturmaktadır. Yukarıda sıralanan çözüm önerilerinin dikkate alınması arz-talep arasındaki dengesizliğin azaltılması katkı sağlayacaktır. Bununla birlikte; alınancak tedbirlerin daha erken ve daha kapsamlı olması uygulamaya konulacak politikaların başarı şansını artıracaktır.

\section{Kaynakça}

Abiad, A., Arao, Mia., Dagli, S., Ferrarini, B., Noy, I., Osewe, P., Pagaduan, J., Park, D. ve Platitas, R. (2020). The Economic Impact of the COVID-19 Outbreak on Developing Asia. ADB Brief, No: 128.

Anh, D. L. T. Ve Gan, C. (2020), The impact of the COVID-19 lockdown on stock market performance: evidence from Vietnam. Journal of Economic Studies.

Baker, S. R., Bloom, N., Davis, S. J., Kost, K., Sammon, M. ve Viratyosin, T. (2020). The Unprecedented Stock Market Reaction to Covid-19. The Review of Asset Pricing Studies, 10(4), 742-758.

Davis, S. J., Liu, D. ve Sheng, X. S. (2021). Stock Prices and Economic Activity in the Time of Coronavirus. Becker Friedman Institute, Working Paper, No. 2020-156.

Economist Intelligence Unit (2020). How Well Have OECD Countries Responded To The Coronavirus Crisis?. https://www.eiu.com/public/

topical_report.aspx?campaignid=response-covid-rank (Erişim: 15.01.2021)

Eichenbaum, M., Rebelo, S. ve Trabandt M. (2020). The TradeOff Between Economic and Health Outcomes of the Covid19 Epidemic. https://voxeu.org/ article/trade-betweeneconomic-and-health-outcomes-covid-19-epidemic (Erişim: 11.01.2021)

Eurostat (2021). Impact of Covid-19 Crisis On Industrial Production. https:// ec.europa.eu/eurostat/statisticsexplained/index.php/ Impact_of_Covid19_crisis_on_industrial_production (Erişim: 06.01.2021)

He, Q., Liu, J., Wang, S. ve Yu, J. (2020). The Impact of Covid19 on Stock Markets. Economic and Political Studies, 8(3), 275-288.

Hong, H., Bian, Z. ve Lee, C. (2021). Covid-19 and Instability of Stock Market Performance: Evidence from the U.S. Financial Innovation, 7, 1-18.

Investing (2021). BIST 100. https://tr.investing.com/indices/ise100 (Erişim 22.02.2021)

Hatmanu, M. ve Cautisanu, M. (2021). The Impact of Covid-19 Pandemic on Stock Market: Evidence from Romania. International Journal of Environmental Research and Public Health, 18, 1-22.

Khatatbeh, I. N., Hani, M. B. ve Abu-Alfoul, M. N. (2020). The Impact of Covid-19 Pandemic on Global Stock Markets: An Event Study. International Journal of Economics and Business Administration, VIII(4), 505-514.

König, M. ve Winkler A. (2020). Covid-19 and Economic Growth: Does Good Government Performance Pay Off?. Intereconomics, 55, 224-231. 
- OECD (2020). Global Economy Faces Gravest Threat Since the Crisis as Coronavirus Spreads. https://www.oecd.org/economy/global-economy-facesgravest-threat-since-the-crisis-as-coronavirus-spreads.htm (Erişim: 25.12.2020)

OECD (2021). Data. https://data.oecd.org (Erişim: 20.12.2020)

Özdemir, L. (2020). Covid-19 Pandemisinin BIST SEktör Endeksleri Üzerine Etkisi. Finans Ekonomi ve Sosyal Araştırmalar Dergisi, 5(3), 546-556.

Öztürk, Ö., Şişman, M. Y., Uslu, H. ve Çıtak, F. (2020). Effects of Covid-19 Outbreak on Turkish Stock Market: A SectoralLevel Analysis. Hitit Üniversitesi Sosyal Bilimler Enstitüsü Dergisi, 13(1), 56-86.

T.C. Sağlık Bakanlığı (2021). Genel Koronavirüs Tablosu. https://covid19.saglik.gov.tr/TR-66935/genel-koronavirustablosu.html (Erişim: 22.01.2021)

Topçu, M. ve Gülal, Ö. S. (2020). The Impact of Covid-19 on Emerging Stock Markets. Finance Research Letters, 36.

UNCTAD (2020). Impact Of The Covid-19 Pandemic On Trade And Development, New York: United Nations Publications.

World Bank (2020). Global Economic Prospects, Washington: International Bank for Reconstruction and Development.

World Health Organization (2021). Coronavirus Disease (Covid-19) Dashboard. https://covid19.who.int/table (Erişim: 10.01.2021) 